\title{
Princípio da Eficiência Econômico-Social no Direito Brasileiro: a tomada de decisão normativo-judicial ${ }^{1}$
}

\author{
Social and Economic Efficiency Principle at the Brazilian's Law: the normative \\ and judicial decision taking
}

Everton das Neves Gonçalves
Universidade Federal de Santa Catarina, Florianópolis, SC, Brasil

Joana Stelzer

Universidade Federal de Santa Catarina, Florianópolis, SC, Brasil

\begin{abstract}
Resumo: O Direito disciplina, para além da moral, a fenomenologia social exigindo olhar multidisciplinar e interdisciplinar; ainda, identificando, na formalidade legal, a realidade social. A Ciência Econômica confere eficácia ao Direito, relevadas, no cálculo econométrico próprio da eficiente tomada de decisão normativo-jurídica, variáveis próprias de inclusão social. Este artigo objetiva identificar o Princípio da Eficiência Econômico-Social (PEES); justificando-se pela necessidade de delimitar categoria teórica distinta de interação econômico-jurídica. Trata-se de pesquisa qualitativa exploratória, de procedimento monográfico, de abordagem dedutiva e técnica de pesquisa bibliográfica. $\mathrm{O}$ artigo conclui pela criação e aplicação de Direito, socialmente inclusor; progressista, eficaz e eficiente; atento ao contexto econômico, político e jurídico tal como preconizado pelo Princípio da Eficiência Econômico Social.
\end{abstract}

Palavras-chave: Princípio da Eficiência Econômico-Social. Análise Econômica do Direito. Direito e Economia.

1 Recebido em: 06/09/2013

Revisado em: 08/10/2013

Aprovado em: 21/02/2014
Abstract: The Law disciplines the social phenomenology forward the moral and it requires a multi and interdisciplinary vision to identify the social reality on the legal formality. The Economic Science gives effectiveness to the Law, if considered the variables of social inclusion at the economic calculus appropriated to the efficient normative and juridical decision. This article objective to identify the Social and Economic Efficiency Principle (SEEP). It's justified by the necessity to delimitate a distinct and theoretical category from the interaction between Economic Science and Law. It's a qualitative and exploratory research, with monographic procedure and deductive boarding and research technique is bibliographic. It concludes by the Law's creation and application that be socially inclusive; progressive, effectiveness and efficient; dealing with juridical, political and economic context like expressed by the Social and Economic Efficiency Principle.

Keywords: Principle of the Economic-Social Efficiency. Economic Analysis of Law. Law and Economics. 


\section{Introdução}

As circunstâncias políticas, jurídicas e econômicas caracterizam o meio social e seu respectivo Direito; logo, entende-se que a política almeja a liberdade da cidadania; enquanto a economia vislumbra a fraternidade no uso dos escassos recursos e, finalmente, a justiça visa o tratamento igualitário dos jurisdicionados. A fenomenologia social deve ser analisada segundo ampla visão, inclusive, econômico-jurídica. O Direito, analisado multi e interdisciplinarmente pela Ciência Econômica, vislumbra efetividade e eficácia, especialmente, se relevadas, no cálculo econométrico próprio da eficiente tomada de decisão normativo-jurídica, variáveis próprias para a necessária inclusão social e para o atendimento dos anseios dos jurisdicionados.

Este artigo trata do Princípio da Eficiência Econômico-Social (PEES) e justifica-se, delimitando, como categoria teórica, distinta possibilidade de interação econômico-jurídica socialmente inclusora; progressista e capacitada para a realização dos Direitos individuais e sociais de forma eficaz e eficiente; permitindo racionalidade e humanização para a norma positivada, sem perder de vista os dilemas da vida, especialmente humana, em meio aos contextos econômicos, políticos e jurídicos.

Enquanto o Direito busca dado critério de justiça, a Ciência Econômica se ocupa do dilema da escassez e da necessidade de eficiência no uso dos recursos produtivos. Justiça e eficiência são metades da mesma verdade que se sobrepõem alternadamente ou se complementam ordenadamente, mormente, segundo a visão determinista de Karl Marx (1982, p. 10); a ação concatenada de Rudolph Stammler (1929, p. 138) ou, ainda, a interação simbiótica entre o Direito - verdade formal e o fenômeno econômico - verdade real.

Objetiva-se, então, a assunção do PEES, como opção de política jurídica, próprio tanto para a elaboração quanto para aplicação da norma como para sua possível análise judicial. 
Se, sob o enfoque sociológico, Max Weber (1964, p. 652-653) esclarece que a lógica jurídica puramente profissional e o Direito abstrato contrariam as expectativas sociais, pois estas são orientadas de acordo com o sentido econômico ou prático-utilitário de uma norma jurídica, entende-se que, em meio às escolhas políticas próprias dos sistemas econômicos constitucionalmente adotados, é imperativo emergir respectivo Direito que deve zelar pelos interesses e prerrogativas, tanto dos incluídos como dos socialmente excluídos; sendo a justiça, equivalente à tomada de decisão pragmática, eficiente e capaz de garantir, ainda, para a pluralidade das sociedades presentes e futuras, a conservação de suas prerrogativas.

A aproximação entre Direito e Economia pode ser vista sob o enfoque do Direito Econômico e das Escolas ${ }^{2}$ da Análise Econômica do Direito (AEDI), segundo o enfoque tradicional da Escola de Chicago - Law and Economics (LaE) ${ }^{3}$, o enfoque Neoinstitucional ou vertente dos Property Rights ${ }^{4}$, o enfoque chamado de Eleição Pública - Public Choice ${ }^{5}$ e, ainda, pelos conhecidos Estudos da Crítica Jurídica (ECJ) ${ }^{6}$. Com visão econômico-jurídica, ainda, são destacados autores como: Ronald Coase

2 Andrés Roemer (1994, p. 4) analisa quatro enfoques da disciplina em questão: o tradicional - de Posner, o neoinstitucional, o da public choice e os Estudos da Crítica Jurídica. Consagrou-se a expressão Law and Economics para designar o enfoque tradicional da Escola de Chicago também conhecido como Institucionalista.

3 Como subsídio bibliográfico ver: Cooter (1988); Hirsch (1988); Posner (1977); Shavell (1987) e Polinsky (1985).

4 A respeito do enfoque neoinstitucional da LaE, podem ser verificadas as obras de Mercuro (1989); Furubotn e Pejovich (1974); Williamson (1989).

5 Enriqueça-se a pesquisa consultando Farber e Frickley (1987); Tullock (1965; 1991); Mueller (1979); Downs (1957); Black (1958); Stigler (1971); Buchanan (1993).

6 Para apreciação histórica do movimento ECJ, ver as obras de Schelegal (1984, p. 391411) e Schwartz (1984, p. 413-455); Altman (1993); bem como do brasileiro Mangabeira (1983). 


\author{
$(1960)^{7}$, Guido Calabresi $(1961)^{8}$, Guido Alpa $(1981)^{9}$ e Richard Allen \\ Posner (1977) ${ }^{10}$.
}

\title{
2 A Análise Econômica do Direito
}

A Ciência Econômica oferece para o Direito o necessário instrumental metodológico orientador das políticas públicas e da tomada de decisão privada; competindo, ao Direito, estipular o justo privado sem descuidar do custo social. Há, entretanto, que se atentar ao fato de que o Direito acompanha as tendências de sua sociedade criadora, especial-

7 Ronald Coase, economista, foi professor de Richard A. Posner, no final dos anos de 1950. Na Virginia University, escreveu divorciando-se das teorias de A. C. Pigou, defendendo a necessária e eficiente reparação do custo social - externalidades, não segundo quem o causou, de forma apriorística, porém, segundo quem melhores - eficientes - condições tivesse para arcar com o ônus da internalização, no cálculo econométrico, principalmente, das chamadas externalidades negativas. Defendeu, como principal axioma, que quando os custos de transação estão zerados, é indiferente a adjudicação de direitos. Para maiores informações, ler Coase (1960).

8 Guido Calabresi foi professor de Yale e trabalhou a questão da distribuição dos riscos através do Torts Law, reconhecendo a reciprocidade de interesses quando da solução do problema das externalidades negativas geradas pela ação danosa que deveriam ser adjudicadas, pelo direito de indenização, segundo critérios de eficiência. Ver sua principal contribuição in Calabresi (1961, p. 499; 1984).

9 Guido Alpa escreveu na Itália, destacando-se: ALPA $(1982,1979,1981)$ e PULITINI, RODOTÀ e ROMANI (1982).

${ }^{10}$ Richard A. Posner é Juiz da $7^{a}$ Corte de Apelação dos Estados Unidos da América em Chicago, Illinois, onde, hoje, também exerce as funções de professor - Senior Lecturer - na Universidade de Chicago. Estudioso do Direito, o Professor Posner, em decorrência de suas pesquisas e da prática judicial elaborou, no final da década de sessenta, trabalhos de pesquisa no campo da interdisciplinaridade entre o Direito e a Ciência Econômica. Para o autor, ficou evidente que a Teoria Econômica é chave crucial de entendimento da atitude social do homem e, assim sendo, deve ser utilizada como parâmetro na descoberta do justo, segundo necessidades deste próprio ser social. Em 1973, Posner publicou, pela primeira vez, sua obra Economic Analysis of Law em que afirmou não pretender, aproximação: sociológica, antropológica ou filosófica do Direito, mas, sim, econômica. A obra, ISBN 978-0-735-56354-4, em sétima edição, no ano de 2007, foi incrementada objetivando apresentar, de forma simples e direta, as diversas possibilidades de aplicação da Teoria Econômica aos mais variados campos da Common Law. Ver Posner (1977, p. 15-16). 
mente, econômico-políticas. Nos Estados Unidos da América (EUA), dos anos de 1960, o ambiente social e ideológico passou a ser favorável à volta do liberalismo político-econômico-jurídico, agora, conhecido como neoliberalismo ${ }^{11}$. Assim, para além do movimento acadêmico-economicista, mormente, em Chicago e Yale; verificou-se a ascensão, nos anos de 1980, de Ronald Reagan, no governo norte-americano; de Margaret Thatcher, no Reino Unido e de Helmut Kohl, na Alemanha, dentre outros que implementaram mudanças radicais de cunho neoliberal, minimalistas de Estado e flexibilizadoras das relações de produção.

Dentre as opções apresentadas para o entendimento do Direito, uma determinou-se em reação vista como de caráter construcionista e de resposta ao Realismo Jurídico norte-americano ${ }^{12}$, em tentativa de volta às stare decisis e à instalação de novo linguajar que convencesse e justificasse a práxis econômica e seu discurso. Ocorreu, dessa forma, uma espécie de transição entre o velho Direito Econômico e o novo Direito e Econo$\operatorname{mia}^{13}$.

${ }^{11}$ Friedrich Hayek (2009, 279 e 280) já havia, em 1944, escrito a obra que defenderia, incondicionalmente, a liberdade e a responsabilidade pessoal; tratava-se do Caminho para a Servidão.

12 Três tipos de oposição ao realismo jurídico norte-americano foram tomadas, a saber: a posição desconstrutivista do sistema vigente, a posição dos propugnadores da codificação do Direito e a dos construtivistas, que originou a Escola do Processo Legal de tendência convencionalista na qual se utilizam as práticas da elaboração racional de decisões que combina tanto a principiologia - base do formalismo, como a policy - prática de interpretação jurídica e adoção de statutories law. Nesse mesmo sentido, ver Horwitz (1980, p. 905-912), como, também, conforme visto em Pacheco (1994, p. 204).

13 Ao abordar o, então, novo discurso de Ronald H. Coase, Bruce Ackerman refere à continuidade entre o velho Direito Econômico e a nova Análise Econômica do Direito explicitando: Somente com o novo análisis económico del Derecho, o movimento se converte em verdadeiro caminho para a ortodoxia realista porque, então, é quando se faz evidente que o realismo está sendo posto em duvida não só aqui e ali, senão em quase todas as partes por juristas que se nutrem de um fundo comum de ideias construtivas. O todo cultural se está fazendo maior que a soma de suas partes. Quando se soma ao novo o velho "análisis económico del Derecho", o resultado não é dois discursos legais especializados e sim um discurso jurídico geral. (em espanhol no original). Ver Ackerman (1988, p. 85). 
Enquanto o velho Direito Econômico cuidava das legislações Antitrustes, de política fiscal e outras de caráter macroeconômico, o novo Direito e Economia (AEDI) ${ }^{14}$ - tratou de aplicar as premissas básicas da Microeconomia, subdivisão metodológica da Teoria Econômica, aos diversos ramos do Direito não, especificamente, afeitos ou ligados às políticas econômicas. Passou, então, a AEDI, a ser aplicada na análise dos campos diversos da Common Law, tais como: os inerentes aos Property Rights, ao Law of Torts e ao Contract Law, além, é claro, dos demais ramos do Direito norte-americano. Richard A. Posner (1977, p. 15-16) foi um dos pioneiros nessa prática ao empregar a Teoria Econômica em ramos como o Direito de Família, o Direito de Propriedade, o Direito Contratual, o Direito de Reparação de Ilícitos Civis, o Direito Penal e o Direito Constitucional, dentre outros.

É evidente que, num primeiro momento, os pensadores racionalistas das Economic Schools não se escusam de terem adotado método ideológico, característico da economia de mercado capitalista. De fato, a AEDI, antes de tudo, é opção de critério de justiça que, ao invés de ser aleatório e político, assume sua origem dentro do próprio Sistema Econômico Capitalista de Mercado. Nos anos de 1960, autores norte-americanos apropriaram-se das máximas da Teoria Econômica e aplicaram-na ao discurso jurídico; assim, Ronald H. Coase, em 1960, publicou seu trabalho The Problem of Social Cost; e Guido Calabresi, no ano seguinte, apresentou Some Thoughts on Risk Distribution and the Laws of Torts. Passados 53 anos, o famoso Teorema de $\mathrm{Coase}^{15}$, enaltecido por George

${ }^{14}$ Em ponto de vista amplo, AEDI refere a toda tendência crítica do realismo jurídico americano que tenha, em sua fundamentação doutrinária, a utilização da Teoria Econômica para a análise do Direito. Por outro lado, em visão stricto sensu, a LaE deve ser entendida como a parte do referido movimento crítico que foi idealizado por Richard A. Posner. A LaE busca a compreensão do universo jurídico partindo de pressupostos e valores metajurídicos pertencentes ao mundo do econômico, aplicáveis, tanto na criação da norma jurídica como na de sua apreciação nos tribunais.

15 Segundo o Teorema de Coase, uma vez inexistentes os custos de transação, tornase indiferente que os direitos sejam determinados previamente, restando, sempre, a possibilidade de realocação deles, segundo interesses dos particulares envolvidos. Resta, sim, papel de relevada importância, para o Direito, no caso de verificação de desvios de mercado - falhas de mercado - ou quando existirem altos custos de transação que 
Joseph Stigler (1987), ainda vige, na releitura que seu autor fez de Arthur Cecil Pigou ${ }^{16}$ (1920). Agora, reestruturado o próprio pensamento de Richard Allen Posner ${ }^{17}$ (2010), então, pragmático, defende-se que a AEDI pode ser utilizada na defesa de interesses, segundo critério único e previamente conhecido. Justamente, ponto crucial da AEDI é o fato de ela espelhar critério preestabelecido, não aleatório, pois, uma vez adotado como ideal de justiça, não mais sofre injunções político-ideológicas outras que não as estritas regras maximizadoras de resultados em mercado-social.

impeçam as partes em conflito de transigirem; além do controle do poder de polícia em relação ao comportamento social dos indivíduos. A princípio, deve ser ressaltado que não se está fazendo apologia ao Estado mínimo e a não funcionalidade do Direito; muito pelo contrário, as instituições administrativo-jurídicas são necessárias em um mundo no qual o estado utópico de mercado de concorrência perfeita não existe. Sobre os custos de transação, ver Coase (1960. p.1-44).

${ }^{16}$ A economia liberal do século XIX, repleta de crises sinalava com inegável necessidade de mudanças que ocorreram no século XX, destacando-se, especialmente, no campo da política, a I Grande Guerra e, após os anos de 1920, a ideia do Estado forte e interventor como regulador e fiscalizador da atividade econômica, em cujo ápice do intervencionismo estatal, se verificou o pensamento de John Maynard Keynes (2012); no campo da economia, o Crash da Bolsa de Nova Iorque e suas desastrosas consequências. Na academia, também, podem ser destacados os trabalhos de Arthur Cecill Pigou, professor de Keynes e inspirador de Coase a justificar a necessidade de se coibir o ganho privado em detrimento do custo social - externalidades, e que, assim, justificava-se a ação do Estado, sob qualquer custo, como propulsora da justiça economia; ideia que vai ser contestada, posteriormente, pelo próprio e pelos adeptos de Ronald H. Coase, defendendo-se, então, a eficiência na internalização das externalidades.

17 Autores como Richard A. Posner e outros da Escola de Chicago - G. Becker, H. Demsetz, F H. Easterbrook, I. Erlich, M. Landes e G. Tullock têm a racionalidade econômica e a eficiência. como valores últimos a serem perseguidos pelo Direito. Formam a corrente majoritária, conforme se vê em Pacheco (1994, p. 58-64) e em Torres Lópes (1987, p 71). No entanto, outros autores como Guido Calabresi, B. Ackerman, P. Bobbit, E J. Mishan e A. M. Polinsky, participantes do setor minoritário da AEDI dito moderado criticam Posner e identificam, além do caráter econômico do Direito, valores outros a serem considerados como os de justiça, lealdade e amor, bem como, as limitações da LaE como, v.g., a distribuição equitativa dos recursos. A partir dos anos de 1990, mesmo Posner passou a adotar posicionamento mais flexível, então, pragmático. Ver em Posner (2010). 
Acredita-se, pois, que o método analítico-interpretativo-construtivista da AEDI torna o Direito jurídico-persuasivo ${ }^{18}$ dentro de processo de análise de custo e benefício esgotando o paradigma jurídico-coercitivo vigente. Destarte, ao invés de exclusiva preocupação em reconstrução do status quo ante, o modelo jurídico-legal, segundo a AEDI, volta-se para o futuro de forma a influir a ação dos indivíduos por meio de conjunto de incentivos e de obstáculos. O Direito, portanto, além de controlador social, passa, funcionalmente, a determinar o comportamento social segundo análise da relação de custo e benefício.

Entende-se, assim, que a prática jurídico-econômica de mercado social, como discurso vigente, deve fazer refletir fenômeno jurídico-social conforme realidade inarredável da previsão legal segundo critérios racional-normativos de maximização de lucros - riqueza - e de eficiência econômica que ocorram dentro de dialética social-econômico-normativa inclusiva e progressista, ainda conforme ao que se defende como Mínimo Ético Legal (MEL).

O anacronismo normativo-econômico, bem como sua interpretação equivocada e ultrapassada, indubitavelmente leva à estagnação e retrocesso no processo de desenvolvimento em contrapasso com a realidade dinâmica mundial. Necessário, pois, repensar a realidade econômico-jurídica nacional a partir de ótica aberta para a razão refratária aos extremismos e conforme as possibilidades do discurso jurídico vigente nas relações sociais verificáveis no contexto globalizante, qual seja, o inerente à economia de mercado neoliberal, naquilo que seja próprio à defesa dos interesses individuais e sociais.

A interação entre a Ciência Econômica e o Direito é, em primeiro momento, surpreendente já que, a princípio, haveria diferença metodológica na compreensão da fenomenologia social por parte de ambas as ciências; entretanto, é interessante verificar que a unicidade de determinado fenômeno pode ser apreciada sob os diversos pontos de vista sem deixar

\footnotetext{
18 No mesmo sentido, ensina Juan Torres Lópes: A moderna Análise Econômica do Direito passará a contemplar as leis, não como fatos passados cujos efeitos vão ser avaliados, mas como sistema de incentivos que influirão decisivamente nas ações futuras. (em espanhol no original). Ver em Torres Lópes (1987, p. 22).
} 
que este continue individualizado e inalterado. A Economia é ciência analítica por natureza e aplica-se ao Direito na medida em que lhe propicia a metodologia necessária para quantificar interesses, analisar procedimentos e indicar soluções com tendências probabilísticas que levem à dissipação dos conflitos e à satisfação das necessidades, bem como à elaboração legislativa. Intenta-se, assim, eliminar a legislação e o julgamento político-volitivo e aleatório. Considerada a etapa capitalista, na evolução dos Sistemas Econômicos, o Direito racional, isto é, direito calculável ${ }^{19}$ se fez e se faz necessário, para que a exploração das diversas atividades econômicas possa ser desenvolvida dentro de perspectiva de segurança jurídica, que impeça as incertezas e instabilidades não permissivas da acumulação. O Estado e o Direito vêm em socorro das necessidades dos empreendedores propiciando, então, as condições mínimas para o desenvolvimento da atividade econômica e social. É o dito elemento coercitivo ${ }^{20}$ que Weber refere estar sob o domínio do Estado que garante a atividade econômica regulando-a e dirimindo seus conflitos.

Com relação ao entendimento conceitual dado à AEDI, podem ser carreadas as contribuições doutrinárias de Kuperberg e Beitz, Santos Pastor e Pedro Mercado Pacheco. Para Kuperberg e Beitz (1983, 21), a Análise Econômica do Direito é a aplicação dos métodos econômicos de análise a problemas de interpretação jurídica. (em inglês no original). Santos Pastor (1989, p. 31, tradução nossa) manifesta a respeito afirmando que a Análise Econômica do Direito é "[...] disciplina, que essencialmente consiste em aplicar princípios e técnicas habituais em análise econômica ao estudo de problemas característicos do ordenamento (sistema)

\footnotetext{
19 No mesmo sentido Max Weber ensina que uma das condições para o desenvolvimento da atividade empresarial, em uma economia capitalista, é o Direito racional, isto é, direito calculável. Para que a exploração econômica capitalista proceda racionalmente precisa confiar em que a justiça e a administração seguirão determinadas pautas. Ver em Weber (1968, p. 251).

20 Diz Weber: [...] segundo a experiência histórica, atrás de toda economia existe um elemento coercitivo atualmente, manejado pelo Estado e, em épocas passadas, amiúde, pelas corporações - e até mesmo uma economia socialista ou comunista dele necessita para por em prática suas ordenações; mas esta coerção, agora não é, precisamente, uma atuação econômica, e sim, tão somente, um meio para assegurá-la. Ver em Weber (1968, p. 10).
} 
jurídico”. Pedro Mercado Pacheco (1994, p. 27, tradução nossa) ensina tratar-se da

[...] aplicação da teoria econômica na explicação do direito. Mais em concreto, é a aplicação das categorias e instrumentos teóricos da teoria microeconômica neoclássica em geral e de um de seus ramos desenvolvido neste século, a Economia do Bem-Estar, em particular, na explicação e valorização das instituições e realidades jurídicas.

Como postulados maiores da doutrina Law and Economics defendem-se, os seguintes: a) Prevalece, como método, na aplicação da Economia ao Direito, o individualismo metodológico, segundo a racionalidade maximizadora economicista; b) As leis jurídicas devem guardar mínima harmonia com as leis econômicas; e c) O Paradigma jurídico deve volver-se para a agilização e fluidez das relações de produção, maximização dos lucros e otimização da produção e utilização da riqueza individual e social.

Para fins de registro de base epistemológica, a específica abordagem do movimento economicista do Direito e, em especial, da AEDI, conta com autores como: Ronald H. Coase (1960), Guido Calabresi (1961 e 1984) e Richard A. Posner (1977) que sustentam a teoria de base quanto à AEDI, sobre a qual autores outros como Santos Pastor (1989), Carlos Otero Días (1966), Hugo Rangel Couto (1980), Juan Torres Lopes (1987), George Stigler (1987), Hans Bernd Schafer, Claus Ott (1991) e A Mitchell Polinsky (1985), dentre tantos, podem contribuir para o entendimento do tema. De outra forma, ainda, são importantes as contribuições de Jeremy Bentham (1974) e seu utilitarismo, de Wilfredo Pareto (1984) e sua teoria de otimização da riqueza, de Kaldor (1939, p. 549-552) e Hicks (1939, p. 696-712) e seu critério de bem-estar e de Wlliam James (1979 e 1987) e seu pragmatismo como suporte teórico das premissas filosóficas da AEDI.

Além de fatores de influência teórico-filosóficos, como o pragmatismo de William James, o utilitarismo Jeremy Bentham e o egoísmo, como método de ética que é, justifica-se, para a estruturação da doutrina 
própria da AEDI, a teoria de Max Weber (1994), em sua obra denominada $A$ ética protestante e o espírito do capitalismo, que trata a respeito do modo racional de pensar as relações sociais, verificando nexo entre crenças religiosas - salvação pela criação da riqueza; a coerência ética da existência - valorização individual do trabalho - e atividade econômica disciplinada.

Consideradas as bases filosóficas para o pensar jurídico-econômico resta, como desideratun nas relações sociais, o equilíbrio político-econômico-jurídico, por meio da negociação de interesses que, em última análise, são recíprocos. É nessa perspectiva de reflexão que se discute o papel do Estado e do Direito para resolução de controvérsias. Os Estados, segundo a pragmática de seus governos, buscam, nas instituições econômico-jurídico-políticas, a maximização de expectativas de forma a ser obtida a maior diferença entre custo e benefício. Defende-se, pois, que se pode distribuir renda e alocar recursos a partir de tomada de decisão racional consideradora do social, fato que o mercado, por si, é incapaz de fazer. Dessa forma, o sistema econômico ideal deve perpassar o mercado globalizado e universalmente regulamentado, sob a égide do PEES, como forma de atenuação entre a planificação - em que se tem a desvantagem de perder o referencial do valor econômico - e a concorrência de mercado - que faz desaparecer as possibilidades de coexistência.

Como desiderato da aplicação econômico-jurídica aos fenômenos sociais, no Sistema Econômico Liberal capitalista que importe em primazia do indivíduo, tem-se, conforme a AEDI, economia do bem-estar pela maximização dos resultados e decisões tomadas em todos os setores da economia de mercado - idealmente, em concorrência perfeita - eliminando-se as deseconomias ou economias externas e igualando-se os custos sociais marginais às receitas sociais marginais. Do ponto de vista econômico, parte-se do pressuposto de que, incrementando a eficiência, se aumenta a riqueza, o que, necessariamente, pode não levar à equidade e à distributividade, haja vista, a desigualdade ${ }^{21}$ que também caracteriza a

21 Enquanto a Ciência Econômica parte do pressuposto da desigualdade, no Direito pode ser intuída a justiça que almeja a equidade. Observa-se, no entanto, que seja em estado de natureza, seja em sociedade e, mesmo que utopicamente igualadas as condições de todos os homens, restam, eles, diferenciados, após algum tempo. Não há conflito real 
distribuição do aquinhoamento dos diversos fatores produtivos entre os sujeitos de direito. Necessário, portanto, é, ao aplicar métodos jurídico-econômicos, ampliar a riqueza, porém, sem descuidar da inclusão social como forma ideal de eliminação das externalidades tal qual defendido pelo PEES e segundo a ação Estatal conforme a garantia do MEL.

\section{Princípio da Eficiência Econômico-Social (PEES) e Mínimo Ético Legal (MEL)}

Conceitual e economicamente eficiência deve ser vista a partir das ideias de Vilfredo Pareto (1984), de Nicholas Kaldor (1939, p. 549-552) e de John Hicks (1939, p. 696-712). Assim a doutrina econômica conhece o que se chama de melhoria de Pareto, ótimo de Pareto e critério Kaldor-Hicks. Pareto tem por ótima, pós-vencidas etapas em arranjos intermediários que impliquem em melhorias, a situação econômica em que é impossível melhorá-la, ou, mesmo, melhorar as condições de um agente, ou a utilidade que ele obtém em sociedade, sem prejudicar a situação, ou a utilidade de qualquer outro agente econômico, ou sujeito de direito. Já, no critério de Kaldor-Hicks, atingido e para além do ótimo de Pareto, ainda se pode obter outros arranjos produtivos, institucionais, pessoais, etc.; desde que, prejudicando terceiros, se os possa compensar.

Resta, pois, novo arranjo do Direito com a Economia, buscando eficiência, sim; porém, dentro de limites determinados pelo Estado, segundo se entende por Mínimo Ético Legal (MEL). Tal arranjo denomina-se Princípio da Eficiência Econômico Social (PEES). Destarte, justifica-se que, se a análise econômica de custos e benefícios pode não considerar critérios distributivos e, preconizando maiores lucros para um grupo, submeter outro a carências; por outro lado, a distribuição regressiva leva a maiores injustiças em termos materiais. Dessa forma, devem ser considerados critérios progressistas de distribuição da riqueza, segundo processo de to-

ou é aparente o conflito entre Economia e Direito; já que, a primeira Ciência, busca a criação eficiente da riqueza; enquanto, à segunda, compete garantir a segurança jurídica e a equidade das relações que não foram previamente determinadas ou cujos custos de transação são inaceitáveis. 
mada de decisão que não leve à estagnação ou inoperância da atividade econômica. Torna-se útil o critério de eficiência de Kaldor-Hicks para a adjudicação do Direito entre os sujeitos de direito, além de programas ou políticas distributivas a serem, cautelosamente, implementados pelo Estado; já que, infelizmente, nem sempre são computadas, no cálculo utilitário decisório as externalidades negativas e positivas. A regulamentação, em busca da eliminação do desequilíbrio social, deve determinar a obrigação de compensação dos desfavorecidos ou destituídos de suas prerrogativas em função da adoção de possibilidades eficientes. Dessa forma, seja nas negociações ou na tomada de decisões, a partir da lógica do jurista-economista, os agentes devem maximizar suas expectativas, eliminando externalidades, através da inclusão destas no cálculo econômico como defendido segundo o PEES. Trata-se da elaboração e aplicação da norma de forma economicamente eficiente, maximizando-se resultados esperados quando da adjudicação de direitos ou da determinação de obrigações, conforme caráter recíproco das ações e interesses, porém, considerando o reflexo social e o custo externo imposto à sociedade presente; ou mesmo, futura, de forma a serem compensados, na totalidade, os prejuízos impostos pelo ganho presente das partes envolvidas. Ainda, tem-se que o PEES considera, no cálculo econométrico, as variáveis de cunho social e temporal que, corretamente valoradas, devem ser internalizadas de forma que a relação de custo e benefício demonstre a realidade das utilidades auferidas quando se sacrificando determinados bens e serviços de outrem; considerado o maior número ou a totalidade dos agentes envolvidos.

Ainda se concorda com Pigou que o custo social não pode se justificar pelo ganho privado; também se concorda com COASE, que interesses recíprocos devem ser equacionados de forma eficiente entre as partes, porém; defende-se que as externalidades geradas pelos arranjos interpartes tem de serem internalizadas e consideradas no eficiente acordo entre as mesmas. Assim, evita-se que, em futuro não remoto, pelo emprego ineficiente de recursos e criação de indicadores mercadológicos falsos verifique-se o caos econômico.

O Direito aplicado de forma eficiente torna-se moral, reduzindo as externalidades na medida em que custos são internalizados quando da violação dos próprios princípios morais. O altruísmo, por sua vez, tam- 
bém não está descartado da lei quando é raciocinado em termos econômicos na forma de derivação de utilidade, por parte de alguém, em relação à utilidade desejada por outrem, conforme a satisfação do próximo.

A aproximação entre o Direito e a Teoria Econômica torna-se possível segundo aplicação do PEES, dadas as restrições materiais, segundo se almeje a equiparação dos níveis de satisfação individuais e coletivos envolvidos no caso concreto, ainda, mediante tratamento equitativo aos iguais e, diferenciado aos desiguais, difundindo-se incentivos para a ação socialmente desejada ou obstáculos para atos condenados pelo acordo social previamente estabelecido em normas e nos costumes. Falhas de mercado distorcem a distribuição ideal de recursos e a alocação eficiente destes restará prejudicada implicando injustiça em função do desperdício e da escassez fazendo urgir a ação do Estado e do Direito para organizar as relações econômico-sociais. Justiça, segundo a ótica do Direito tradicional, é dar, a cada um, o que lhe pertence - justiça corretiva para Aristóteles (1992, p. 95), ou segundo critério distributivo, ainda, conforme o Mestre macedônio implica em retribuir na proporcionalidade em que cada um tenha contribuído para o bem estar social, ou seja, tratar os iguais com igualdade e os desiguais com desigualdade. Ademais, justiça é fazer, aos outros, o que se gostaria que fosse feito a si - alteridade. Justiça, segundo a ótica econômico-jurídica, refere à compensação de cada agente, no mercado, segundo seu interesse ${ }^{22}$ (Willingness to Pay ou Willingness to Accept).

Segundo o PEES, pela interação entre os interesses em disputa envolvidos nas relações sociais, deve ser perquirida solução que otimizando o interesse das partes, seja capaz de relevar o interesse de terceiros que devem ser compensados por possíveis prejuízos causados. Ainda, dentro da ótica econômico-pragmática, a justiça deve ser alcançada pela composição ideal das partes, relevados os interesses sociais reciprocamente considerados. Para tanto, a Justiça no Direito, seja em esfera normativa ou judicial, implica na tomada de decisão que leve em consideração os

\footnotetext{
22 Posner (1977, p. 313-352) trabalha a questão da justiça distributiva, bem como, da justiça corretiva, a partir de Aristóteles, afirmando que é necessário corrigir o senso comum de que as ideias Aristotélicas, bem como Kantianas de justiça são mais aceitáveis, moralmente, do que aquelas próprias de uma visão pragmática e instrumental.
} 
questionamentos indissociáveis do PEES, tais como: a) A inclusão do maior número de variáveis no cálculo econométrico de custo e benefício para a tomada de decisão econômico-jurídica; b) A consideração; para fins de cálculo e distribuição de benefícios ou imposição de custos - adjudicação de direitos, da totalidade dos agentes econômicos e das partes envolvidas, ou que venham a sofrer reflexos em virtude da tomada de decisão econômico-jurídica; c) $\mathrm{O}$ primado da distribuição e redistribuição dos escassos recursos em função da eficiência econômico-social, segundo o Mínimo Ético Legal determinado pelo Estado; d) A apreciação do caso concreto de forma eficiente, segundo expectativas da AEDI, eliminando-se os reflexos das externalidades individuais ou coletivas que venham a determinar injustificáveis custos sociais, bem como, os reflexos da ação presente com relação às gerações futuras e; e) A avaliação dos resultados do sistema jurídico e de sua concreta aplicação a partir da consideração dos incentivos indutores ou obstantes da ação social.

Nesse sentido, a utilização cuidadosa de critérios econômicos harmonizados com objetivos de justiça e bem-estar social representa alternativa para regras de Direito próprias do desenvolvimento. Necessária, pois, é a busca de mínimas condições de justiça asseguradoras e mantenedoras da liberdade no exercício da atividade econômica, uma vez que se reconhece, no estado de concorrência perfeita, no qual não impere o despotismo dos economicamente poderosos, o estado utópico do sistema econômico. O resultado do modus operandi dos agentes econômicos, inseridos em contexto regulamentado, é, em última instância, a defesa de seus interesses pessoais e diretos, tais como: a sobrevivência e a satisfação de suas necessidades vitais, dentre outros; de modo racional, através do uso eficiente dos escassos recursos, seja, por meio do indicativo do mercado em primeira instância ou, na falha deste, através da regulamentação que deve, invariavelmente, defender o interesse econômico-social ${ }^{23}$, segundo o PEES.

${ }^{23}$ Segue-se a lição de Rudolf Von Jhering para afirmar que $o$ Direito é o interesse juridicamente protegido; acrescentando-se que, no mundo hodierno, interesse é a manutenção de patamares desenvolvimentistas eficientes nas relações sociais (JHERING, 1946, p. 189). Oscar Dias Corrêa, socorrendo-se em Bobbio, ensina que a decisão individual, consciente ou não, na maioria das vezes, acabará por conduzir à busca do bem 
Não se pode esquecer que a humanidade cresce globalmente e, a transitoriedade da vida individual não representa, nem justifica o isolacionismo doentio do poder ineficiente, egoísta, despótico e descomprometido com a própria sobrevivência e a dos demais componentes da humanidade; assim como, não justifica a ganância que desconsidera o social; nem a inércia que aumenta o fardo do próximo. Muito menos, justifica-se a destruição do suporte material da vida na Terra, uma vez que se entende, dentro de perspectiva progressista e includente, ser, a riqueza social, individualmente apropriada, porém, e sempre, segundo o eficiente uso comprometido pelo PEES.

É nessa perspectiva de reflexão que se discute o papel do Estado, do Direito e do mercado. Os indivíduos, em mercado, buscam, nas instituições econômico-políticas a maximização de suas expectativas de forma a ser obtida a maior diferença entre custo e benefício, consideradas todas as contingências negativas para negociação. Tem-se, então, tal como ensina Adam Przeworsky (1995, p. 98), papel preponderante para o Estado moderno, na medida em que se distribui renda e aloca recursos que o mercado é incapaz de fazer em função de imperfeições como, a monopolização, e a ineficiência de seus agentes. Em que pese o afirmado, lembre-se que o Sistema Capitalista neoliberal de mercado, por sua vez, se autoajusta, entretanto, mediante concessões de cunho social, já que não pode ad perpetun proceder com a acumulação que concentra, assim como, em virtude da necessidade de serem operadas funções não mercadológicas, variáveis que devem ser internadas no cálculo econômico segundo visão progressista.

Acredita-se que a AEDI deve servir a um Aparelho de Estado ágil, atuando na ordem econômica, de forma normativa e complementar, dei-

coletivo: Esquecem-se os excessos individualistas se o homem acaba por compreender que não só não pode viver só, como sua tranquilidade (felicidade) depende da tranquilidade que os outros homens possam também usufruir. Não se trata, pois, de ação consciente, nem se precisa recorrer ao contratualismo, à noção de contrato social que se estabeleça; mas de um objetivo que se alcança pela compreensão da coexistência, da convivência, inconsciente e progressivamente, pela própria experiência vivida pela Humanidade, sem necessidade de desvendar nas doutrinas contratualistas o fundamento. Ver em Corrêa (1994, p. 144-145). 
xando para a própria sociedade, a partir de marco regulatório conforme ao MEL e ao PEES, a escolha racional e eficiente para a adjudicação da riqueza disponível; inclusive, intervindo, quando da verificação de altos custos de transação para a solução das lides sociais ou para a correção de falhas de mercado.

Segundo o PEES, é possível a acomodação, nos termos de práxis ideológico-normativa, entre os fins racionais economicistas do Direito e a necessidade elementar de equidade - oportunidades: em recursos, emprego, educação, bem-estar social mínimo. Em termos doutrinários, trata-se do possível conciliar entre Rawls e sua Teoria da Justiça Equitativa, Dworkin e sua Chain of Law e Habermas e sua Razão Comunicativa na tomada de decisão com a racionalidade e ética da eficiência própria da AEDI. Tal acomodação normativa questiona a aceitação ou condenação do Direito Individualista voltado para o uso exclusivo da propriedade, depois de desconsiderada a utopia do ter comunitário pela partilha social em detrimento do apropriar racional ${ }^{24}$. Resta inexorável que nenhuma política, ideologia ou fragmento de Direito, pensamento utópico ou pragmático pode vir a ser a ultima ratio caso não se verifiquem as seguintes máximas: a um, é absolutamente necessária a reforma íntima da vontade racional dos indivíduos submetidos ao paradigma jurídico-normativo vigente, que, antes de ser cogente, deve ser persuasivo, e, a dois, é imprescindível a adoção de uma nova-velha perspectiva de relações entre homens, tal como Aristóteles pregou com sua doutrina do meio-termo para a negociação. Por meio da reforma íntima, a partir da educação e do amadurecimento dos processos cognoscitivos; supera-se a insanidade dos demais, assim como, não se aceitando qualquer forma de imposição violenta, incapaz de convencer, elimina-se o gérmen do revanchismo. Pela mudança do paradigma jurídico-normativo refletindo o amadurecimento do homem como ser humano, visando o respeito à sua individualidade de forma a

${ }^{24} \mathrm{O}$ apropriar racional, tal como Epicuro entendeu deve ser visto de forma a considerar todas as variáveis obtendo-se uma perspectiva maior e mais precisa em relação aos fatos e excluindo-se o imediatismo da satisfação momentânea sem levar em conta os reflexos no futuro dos atos presentes. O apropriar racional seria eficiente, conforme Posner, hedonista, segundo Epicuro, utilitarista, como ensina Jeremy Bentham, preocupado com o futuro - político - mantenedor da ordem - social e assegurador de direitos - jurídico. 
que este não sofra e nem faça sofrer aquilo que, outrem, poder-lhe-ia impor, e que não lhe fosse aprovado implementa-se a alteridade.

Entretanto, na atribulação da vida moderna, predominam padrões ético-comportamentais que não alcançam níveis de excelência próprios do homem integral - ser humano consciente e capaz de amar o outro e, sim, apenas e tão somente, arremedam-se expressões pequenas desse mesmo homem - ser que possui a essência da Divindade - como mero consumidor, empresário, trabalhador, profissional, agente econômico ator do teatro mercadológico. No egoísmo da tomada de decisões de forma racional e eficiente resta, para o Planeta habitado, a integração em processo que torna evidente, não mais, a acumulação local de capitais e, sim, a lógica de exploração social dos recursos que passam, então, a serem disputados para usos eficientes, já que, as irracionalidades não podem mais ser toleradas quanto aos escassos recursos da natureza, não renováveis. A utopia capitalista é o caminho que se apresenta possível para a união dos egoísmos individuais, pelo fato do homem ter como imprescindível sua sobrevivência, levando-o a convencer os demais da inexorabilidade da ação conjunta sob a pena do total extermínio; restando, por consequência da busca do bem-estar de uns, a salvação e segurança de outros. Não há mais espaço para o isolamento e, neste contexto, necessário é o repensar de nova Teoria Geral do Direito que, flexível, abandone o ranço dogmático de tradição individualista embasado em conceitos absolutistas e volva-se para a normo-instrumentalização moderna, eficiente e racional de melhor aproveitamento da riqueza satisfazendo, por fim, os anseios individuais e sociais.

As atuais condições de vida forçam a modificação do paradigma comportamental no início do terceiro milênio e, por consequência, impõem a revisão dos institutos jurídico-econômico-normativos, assim, os problemas e soluções - tomada de decisões - encaminham-se para perspectiva global. Evidente, no entanto, é que a grande maioria da humanidade, ainda não educada, transgride sua própria lei de autopreservação.

Utilizar a Teoria Econômica para interpretar ou analisar o Direito significa utilizar método dedutivo de prognósticos em função da norma analisada objetivando a produção de determinado comportamento social 
desejado. No ambiente integrado, necessária é a busca de mínimas condições de justiça asseguradoras e mantenedoras da liberdade regulada e o exercício da atividade econômica, uma vez que se reconhece, em um estado de mercado-social, o estado utópico do sistema econômico que, se não verificado, em função de diversos óbices, tais como: a falta de mobilidade dos fatores produtivos, a desinformação por parte dos agentes econômicos, a concentração empresarial em virtude da economia de escala, o custo social das externalidades, e outros fatores de ordem estrutural e circunstancial; deve ser perseguido, segundo o ambiente institucional e as condições econômicas que propiciem, apesar da existência das referidas falhas de mercado, a sobrevivência socioeconômica racional e eficiente em perspectiva de equilíbrio dinâmico nacional, regional e, quiçá, global.

Ao Direito compete dois papéis: a um, ser inquestionável instrumento de controle social organizando a sociedade e, a dois, cumprindo sua função social, tornar-se adequada forma para a consecução de objetivos e metas em sociedade - funcionalização do Direito; como que tornando racional o uso individual da riqueza social e escassa. Possível, então, pensar inovadora Teoria Geral do Direito que, a partir da aplicação dos institutos da Teoria Microeconômica, possa embasar a criação e a aplicação da norma jurídica de forma eficiente e socialmente inclusora, maiormente, se considerados os parâmetros de internalização das externalidades segundo o PEES e o MEL.

Meta específica, para o Direito, passa a ser a obtenção de sonhada estrutura de convívio social em que, economicamente, os Custos Marginais Privados (CMgpr) e Públicos $(\mathrm{CMgPu})$ sejam igualados às Receitas Marginais Privadas (RMpr) e Públicas ( $\mathrm{RMgPu}$ ). Compatibilizam-se, em termos de práxis ideológico-normativa, os fins racionais economicistas do Direito e a necessidade elementar de equidade através do PEES, uma vez adotado o apropriar individual racional - uso eficiente dos recursos e relevadas as consequências sociais - externalidades. Para tanto, a modificação social perpassa a necessária reforma íntima - obtida pela educação e pelo amadurecimento dos processos cognoscitivos - da vontade racional dos indivíduos submetidos a determinado paradigma jurídico-normativo que, persuasivo, antes de ser mero controlador social, deve determinar políticas econômico-sociais, por meio de sistema de incentivos e obstácu- 
los à ação, inibindo qualquer forma de imposição violenta. A mudança do paradigma jurídico-normativo deve refletir o amadurecimento do homem e o respeito à sua individualidade e à alteridade.

Através de atitude interdisciplinar entre a Ciência Econômica e o Direito, pode ser percebido instrumental analítico-interpretativo próprio ao emprego da AEDI; mormente, por meio do PEES, partindo do pressuposto de que o Direito se desenvolve em ambiente orientado pelo interesse econômico e que alternativas idealizadas já fracassaram diante dos egoísmos que caracterizam o sistema de trocas. Propõe-se, então, como viável o PEES, como critério orientador para criação e aplicação das normas de Direito que, assim atentam para o MEL, disciplinando o apropriar e o usar da riqueza social, individualmente apropriada, em sociedade, ainda, lembrando-se que, o homem, sendo mais que seus desejos materiais, é ser espiritual e social que necessita da sociedade para, assim, usufruir com plena intensidade o seu direito de vida.

\section{Conclusão}

A norma jurídica deve ser criada e aplicada segundo escala de valores que não permita o uso irracional ou ineficiente da riqueza gerada, do meio ambiente e do esforço pelo trabalho. Para tanto, torna-se imperiosa a interatividade entre as Ciências Econômicas e o Direito; como também, entre os interesses econômicos e a premência em desfazer as desigualdades; tal qual convergência entre os ideais individualistas, sociais e os princípios econômicos.

Inserida no estudo do Direito na década de sessenta, a AEDI faz questionar sua racionalidade econômica e apresenta capacidade metodológica para a análise do fenômeno jurídico. Os defensores racionalistas da AEDI e das Economic Schools não negam terem adotado critério de justiça ideológico, característico da economia de mercado capitalista.

A tendência, no campo das ações normativas e judiciais deve visar à tomada de decisões universais rompendo com as resistências individualistas, pois, como primeira razão, a humanidade tem de sobreviver, o Planeta tem de continuar vivendo e o progresso do homem em direção à sua ori- 
gem Divina torna-se inexorável. A Microeconomia apresenta parâmetros técnicos para a tomada de decisão segundo dadas variáveis para indicar a solução eficiente, inclusive, própria ao ora defendido PEES, que, afetando a totalidade dos indivíduos envolvidos e elidindo suas crises; não deve propiciar externalidades aos demais atributos da realidade; quais sejam: a sociedade presente e as futuras gerações - que perpetuam a inteligente ação humana, a natureza - que mantém a vida em condições ecológicas; assim como, aos atributos da idealidade como podem ser lembrados os valores da justiça, da honestidade, do belo, do correto, do amável, do razoável, do espiritual, da Divindade.

Pelo que se afirma, intui-se, em visão holística, que, tanto o Direito, a Ciência Econômica, a Economia, a Sociologia, a Filosofia, a História, a Ecologia, a Psicanálise e tantos outros ramos do conhecimento humano, podem, de forma interdisciplinar, contribuir para a ética de alteridade. Nesse diapasão, o que se defende é o convencimento e a persuasão. Por consequência, em virtude da estruturação e interpretação do Direito resta defender-se o Direito Persuasivo, flexível, desconectado dos ranços dogmáticos de tradição individual-absolutista e dirigido para a instrumentação moderna de caráter racional-eficiente de melhor aproveitamento da riqueza social e individualmente apropriada. Compete, para o Direito, ideal de justiça próprio da sociedade eficiente, que avalie os benefícios e os custos advindos da tomada de decisão individual e social, em ambiente institucional de mercado-social regulado pelo Estado conforme ditames do MEL. O sistema econômico interage com o jurídico-institucional; consequentemente, o Estado e o Direito assumem papel defensor da ação dos indivíduos, segundo suficiente flexibilidade para a adjudicação de direitos e fixação de obrigações.

Os institutos e premissas do meio social e institucional de mercado delineiam o proceder racional do homo oeconomicus que, não obstante, persegue objetivos outros, inclusive sociais, em amplo sentido, através do PEES. Este, como metodologia normativa e normativo-analítico-interpretativa da Ordem Jurídica, sugere a adoção, do que se considera o Sistema Econômico Líbero-Social ou economia de mercado-social disciplinada pelo MEL Estatal; prevalecendo o livre arbítrio das escolhas, em meio à atitude socialmente responsável, de maximização dos interesses indivi- 
duais que, por sua vez, devem ser negociados considerando-se a natureza recíproca e futura das suas consequências quando da tomada de decisões por parte dos agentes econômicos.

Dadas as restrições materiais, escassez, segundo se almeje a equiparação dos níveis de satisfação individuais e coletivos e; mediante a difusão do tratamento equitativo aos iguais e um tratamento diferenciado aos desiguais, promover-se-á justiça, em perspectiva econômico-jurídica, ao serem difundidos incentivos para a ação socialmente desejada e obstáculos para a insanidade egoísta. A partir de tais considerações, sugerem-se as seguintes estratégias no intuito de tornar o Direito justo e capaz de viabilizar condições sociais asseguradoras do almejado desenvolvimento: a) demonstrar que, no binômio fato sócio-econômico-político versus norma, as ciências sociais devem interagir em visível processo dialético; b) apontar procedimentos e máximas interpretativo-jurisdicionais na esfera da AEDI que legitimem a prática econômica global, desburocratizada e livre dos resquícios fundamentalistas extremados; c) levantar estratégias que viabilizem o sistema econômico líbero-social dentro de perspectiva de interação entre interesses capitalistas e necessidades sociais; e) avaliar a crise jurídico-normativa do Direito em função da crise econômico-social; f) evidenciar que os padrões jurídico-normativos expressam-se como oriundos do poder político e econômico, mas, indubitavelmente apresentam-se eficazes desde que observadas e consideradas a articulação de valores e anseios sociais; g) avaliar o controle jurídico interpretativo-normativo da atividade econômica-grau de intensidade e necessidade; $h$ ) verificar a crise existente entre a ineficiência das regras de Direito e a busca da eficiência econômica, viabilizando soluções para que a aproximação das esferas normativas não se torne impossível em relação à realidade econômico-social; e i) constatar a mudança do paradigma mecanicista-procedimental para o modelo holístico-interativo nos diversos campos do conhecimento, em especial, das Ciências Sociais como o Direito e a Economia.

O paradigma de uma Ordem Jurídica Econômica de vanguarda, segundo a AEDI, deve volver para a agilização e fluidez das relações de produção, maximização dos lucros e otimização no uso da riqueza, ainda considerando a inclusão social para o calculo econômico. Portanto, determinando políticas econômicas progressistas, as leis jurídico-econômicas 
devem buscar a eficiência social para a adjudicação dos diversos fatores de produção objetivando o desenvolvimento e a garantia da seguridade e certeza jurídica em pragmática legalista que combine a racionalidade material do economista e a formal do jurista, conforme consenso para a governabilidade substantiva e a inclusão social segundo o PEES.

A política de Estado minimalista justifica-se no fortalecimento da sociedade civil e na consecução complementar da ação estatal na atividade econômica, implementando padrões de distributividade e equidade capazes de propiciar a inclusão de todos os cidadãos presentes, respeitados os interesses das gerações futuras. A AEDI adapta-se à defesa do Estado Líbero-Social, na medida em que permite prioridade para a tomada de decisão segundo o PEES, desde que, invariavelmente, maximizando-se o uso da riqueza para os participantes do processo de desenvolvimento, mormente, integrados, eliminando-se as externalidades causadas pela ação no mercado-social e possibilitando-se a negociação para a consequente diminuição dos custos de transação.

Ao Direito compete indicar as medidas de política jurídico-econômica próprias para a justiça econômica, segundo o PEES, adequadas para a apreciação teórico-jurídica do mundo real, sob pena de esterilidade da lei. Em situação ideal de mercado Líbero-Social, maximizada resultará a utilidade dos escassos recursos e será verificada justiça se forem associadas as ideias de justiça distributiva, comutativa e eficiente segundo adjudicação racional da riqueza e respectiva compensação daqueles que sofrerem externalidades advindas do processo econômico de mercado-social, respeitando-se, definitivamente, o outro - alteridade.

Constatada a necessidade de adoção de inovadora perspectiva para a criação e análise do Direito segundo pluralismo Econômico Líbero-Social, pode ser inferida a necessária síntese paradigmática jurídico-econômica principiologica, principalmente, estipulando a ideologia econômico-política adotada pela sociedade e a determinação das formas de relacionamento entre os diversos agentes econômicos sempre em favor da transigência e da negociação quando da adjudicação de direitos, segundo seja possibilitado o melhor uso da riqueza individual e social; ou, ainda assim, possam ser totalmente internados os custos que foram determina- 
dos sobre terceiros presentes ou para as futuras gerações em virtude das ações praticadas pelos agentes públicos ou privados. Deve, pois, o Direito, indicar quanto de determinado bem, considerado individualmente, se está disposto a para a implementação da riqueza de outro, segundo adoção do MEL e do PEES, sob pena de esterilidade normativa.

Os métodos analítico-interpretativo-construtivistas da AEDI e do PEES tornam possível a criação de um Direito jurídico-persuasivo segundo processo de análise de custos e benefícios, esgotando o paradigma jurídico-coercitivo vigente. O Direito, segundo a AEDI, deve volver-se para o futuro de forma a influir a ação dos indivíduos através do conjunto de incentivos e de obstáculos, a partir da conquista individual, buscando-se o ponto de equilíbrio que, economicamente, corresponde a aquele em que os custos sociais, as receitas sociais, os custos privados e as receitas privadas são idênticos. Da mesma forma, o paradigma jurídico-persuasivo, não pode ser indiferente ao pluralismo Líbero-Social, adotando a liberdade para a tomada de decisão que, sem embargo, não pode desconsiderar os reflexos sociais causados e, observando o PEES, deve internalizar, de forma racional-econômica, por meio do cálculo econométrico, os ganhos e perdas individuais e sociais de forma que o ganho individual não ocorra pela imposição de custo social. Dessa forma, a riqueza, considerada em seu caráter absoluto e privatista, tem seu efetivo papel social, conforme uso racional. A responsabilidade pelo uso social da riqueza individualmente apropriada, antes de imposição é necessidade que torna a convivência dos indivíduos pacífica, assim como, eficiente uma vez que, se garantida a propriedade privada, não se deixa de, também, assegurar a necessária geração de riqueza que deve, assim, traduzir a consequente criação de novas oportunidades de emprego de recursos para a sociedade que, então, passa a ser beneficiada pelo uso racional da riqueza social e individualmente apropriada. Da mesma forma, o indivíduo é favorecido por sua inclusão no rol daqueles que recebem os benefícios sociais de uma coletividade que cresce pelo uso racional de seus bens.

Seguramente, a ação conjunta advinda de tal intento fortifica o desenvolvimento universal, uma vez superada a etapa dos regionalismos, segundo negociação eficaz dos termos da globalização, da internacionalização de mercados e da abertura econômico-política neoliberal, sob pena 
de, não o fazendo, se procrastinar o grande resultado desejado: um mundo melhor, no terceiro milênio, livre de conflitos gerados pela insensatez do radicalismo e no qual se vislumbre o definitivo desenvolvimento.

\section{Referências}

ACKERMAN, Bruce. Del realismo al constructivismo jurídico. Tradução Juan Gabriel López Guix. Barcelona: Editorial Ariel. 1988. ALPA, Guido et al. Interpretazione giuridica e analisi economica. Milano: Giuffrè. 1982. . Interpretazione economica del diritto. Rivista del Diritto Commerciale, Milano,: F. Vallard, ano 1979, Lul.-Dec., 1981. ALTMAN, Andrew. Critical Legal Studies: a liberal critique. New Jersey: Princeton University Press, 1993.

ARISTÓTELES. Ética a Nicômacos. Tradução Mário da Gama Kury. 3. ed. Brasília, DF: UnB, C 1985, 1992.

BENTHAM, Jeremy. Uma introdução aos princípios da moral e da legislação. Tradução Luiz João Baraúna. São Paulo: Abril Cultural, 1974. (Coleção Os Pensadores. v. XXXIV)

BUCHANAN. James M. Custo e escolha uma indagação em teoria econômica. Tradução Luiz Antonio Pedroso Rafael. São Paulo: Inconfidentes, 1993.

CALABRESI, Guido. El Coste de los accidentes: análisis económico y jurídico de la responsabilidad civil. Tradução Joaquin Bisbal. Barcelona: Ariel, 1984.

Some thoughts on risk distribution and the law of torts. Yale Law Journal, Yale, v. 70, p. 499, 1961.

COASE, Ronald H. The Problem of social cost. The Journal of Law and Economics, Chicago: Chicago University Press, v. 3, p. 1-44, 1960. COOTER, Robert D.; ULEN, Thomas. Law and Economics. New York: Harper Collins Publishers, 1988. 
CORREAA, Oscar Dias. O sistema político-econômico do futuro: o societarismo. Rio de Janeiro: Forense Universitária, 1994. pp. 144-145. DOWNS, Anthony. An economic theory of democracy. New York: Harper and Row, 1957.

FARBER Daniel A.; FRICKLEY Philip P. The jurisprudence of public choice. Texas Law Review, Texas, v. 65, n. 5, abr. 1987.

FURUBOTN, Eirik; PEJOVICH, Svetozar. Introduction: the new property rights literature. The Economics of Property Rights, Ballinger, 1974.

HAYEK, Friedrich. O caminho para a servidão. Lisboa: Edições 70. 2009.

HICKS, John. The foundations of welfare economics. Economic Journal. London: Royal Economic Society, v. 49, n. 196, p. 696-712, 1939.

HIRSCH, W. Z. Law and economics: an introductory analysis. 2. ed. San Diego, CA: Academic Press Inc. 1988.

HORWITZ, Morton J. Law and Economics: science or politics. Hofstra Law Review, Available at: http://scholarlycommons.law.hofstra.edu/hlr/ vol8/iss4/2, n. 8. Iss. 4, Article 2. 1980. p. 905-912.

JAMES, William. The varieties of religious experience pragmatism: a pluralistic universe. The Meaning of Truth. Some Problems of Philosophy Essays. New York: Literary Classics of the United States, Inc., 1987.

. Pragmatismo e outros: textos coleção os pensadores. Tradução Jorge Caetano da Silva, Pablo Rubén Mariconda. São Paulo: Abril Cultural, 1979.

JHERING, Von Rudolf. La dogmática jurídica. Buenos Aires: Losada, 1946.

KALDOR, Nicholas. Welfare Propositions in Economics and Interpersonal Comparisons of Utility. Economic Journal, London: Royal Economic Society, v. 49, n. 195, p. 549-552, 1939. 
KUPPERBERG, Mark; BEITZ, Charles. Law Economics and philosophy: a critical introduction with applications to the law of torts. Totowa, New Jersey: Roman and Allan Held, 1983.

MANGABEIRA, Roberto Unger. The critical legal studies movement. Harvard: Harvard University Press, 1983.

MARX, Karl. Para a crítica da economia política: Salário, preço e lucro; Coleção Os Economistas. Introdução Jacob Gorender; Tradução Edgar Malagodi et al. São Paulo: Abril Cultural, 1982.

MINDA, Gary. Los Movimientos del Derecho y la Economía y de los Estudios Jurídicos Críticos en el Derecho Norteamericano. In: MERCURO, Nicholas. Law and Economics. Boston: Kluwer Academic Publishers. 1989.

MOREIRA, Vital. A Ordem Jurídica do Capitalismo. Lisboa: Centelha, 1978.

MUELLER, Dennis C. Public choice. Cambridge: Cambridge University Press, 1979.

OTERO DIAS, Carlos. Una investigación sobre la influencia de la economía en el derecho. Madrid: Instituto de Estudios Políticos. Artes Gráficas Marisal, 1966.

PACHECO, Pedro Mercado. El Análisis económico del derecho: una reconstrucción teórica. Colección El Derecho y la Justicia. Madrid: Centro de estudios Constitucionales, 1994.

PARETO, Vilfredo. Manual de economia política. Tradução João Guilherme Vargas Neto. São Paulo: Abril Cultural, 1984. (Coleção Os Economistas)

POLINSKY, A. Mitchell. Introducción al análisis económico del derecho. Barcelona: Ariel Derecho, 1985.

POSNER, Richard. Economic analysis of law. 7. ed. Boston: Austin: Kluwer. 2007.

POSNER, Richard. Director, pragmatismo e democracia. São Paulo: Forense. 2010. 
PRZEWORSKY. Adam. Estado e economia no capitalismo. Tradução Argelina Cheibub Figueiredo e Pedro Paulo Zahluth Bastos. Rio de Janeiro: Relume-Dumará, 1995.

RANGEL COUTO, Hugo. La Teoría económica y el derecho. México: Porruá, 1980.

ROEMER, Andrés. Introducción al análisis económico del derecho. Tradução José Luis Pérez Hernandez. México: Fondo de Cultura Económica, 1994.

SANTOS PASTOR. Sistema jurídico y economía: una introducción al análisis económico del derecho. Madrid: Tecnos, 1989.

SCHAFER CLAUS OTT, Hans-Bernd. Manual de análisis económico del derecho. Madrid: Ed. Tecnos, 1991.

SCHELEGAL, John H. Notes Toward an Intimate, Opinionated and Affectionate History of The Conference on Critical Legal Studies.

Stanford Law Review: Stanford Law's School, v. 36. n. 1 e 2, p. 391411, janeiro de 1984.

SCHMID Allan A. Law and Economics: an institutional perspective. In: MERCURO, Nicholas. Law and economics. Boston: Kluwer Academic Publishers, 1989.

SCHWARTZ, Louiz B. With Gun and Camera Through Darkest CLS - Land. Stanford Law Review, Stanford, v. 36, n. 1, , p. 413-455, Jan. 1984.

SHAVELL Steven. Economic analysis of accident law. Cambridge: Harvard University Press, 1987. p. VIII, 312.

STAMMLER, Rudolph. Economía y derecho - la concepción materialista de la historia: una investigación filosófico social. Madrid: Editorial Réus, 1929. p.138.

STIGLER, George J. The theory of price. 4. ed. New York: Macmillan Publishing Company, 1987.

TORRES LÓPES, Juan. Análisis económico del derecho. Madrid: Tecnos, 1987. 
TULLOCK, Gordon. The politics of bureaucracy. Washington D.C.: Public Affairs Press, 1965.

. Law and public choice: a critical introduction. Chicago: The University of Chicago Press, 1991.

WEBER, Max. Economía y sociedad: esbozo de sociología comprensiva. Tradução José Medina Echavarriá et al. México: Fondo de Cultura Económica, 1964.

. Max: a ética protestante e o espírito do capitalismo. 9. ed. Tradução Irene de Q. F. Szmrecsányi. São Paulo: Pioneira, 1994. WILLIAMSON, Oliver E. Las Instituciones económicas del capitalismo. México: Fondo de Cultura Económico, 1989.

Everton das Neves Gonçalves é Graduado em Direito pela Faculdade de Direito Padre Anchieta de Jundiaí/SP e em Ciências Econômicas pela Universidade Federal do Rio Grande (FURG/RS); Especialista em Administração Universitária pela FURG/RS; Especialista em Comércio Exterior e Integração Econômica no MERCOSUL pela FURG/RS; Mestre em Direito, na área de Instituições JurídicoPolíticas pela Universidade Federal de Santa Catarina (UFSC/SC); Doutor em Direito, na área de Direito Econômico pela Universidade Federal de Minas Gerais - UFMG/MG; Doctor en Derecho, área de Derecho Internacional Económico por la Universidad de Buenos Aires (UBA/Bs.As) - Argentina; Professor de Analise Econômica do Direito e de Direito Econômico na UFSC/SC; Coordenador do Centro de Estudos Jurídico-Econômicos e de Gestão para o Desenvolvimento (CEJEGD) do Centro de Ciências Jurídicas da UFSC/SC; Professor credenciado no Programa de Pós-Graduação em Direito da Universidade Federal de Santa Catarina (UFSC/SC).E-mail: evertong@vetorial.net.

Endereço profissional: Programa de Pós-Graduação em Direito do Centro de Ciências Jurídicas da Universidade Federal de Santa Catarina, Campus Davi Ferreira Lima, Trindade, Florianópolis, SC; CEP 88040-900. 
Joana Stelzer é Doutora e Mestre em Direito na área de Relações Internacionais pela Universidade Federal de Santa Catarina (UFSC). Professora do Departamento de Administração do Centro Sócio Econômico da (CAD/CSE/ UFSC). Subcoordenadora do Centro de Estudos Jurídico-Econômicos e de Gestão para o Desenvolvimento (CEJEGD). Coordenadora de Tutoria do Curso de Administração Pública do Programa Nacional de Administração Pública (PNAP).E-mail: contatojoana@yahoo.com.br.

Endereço profissional: Curso de Graduação em Administração, Centro Socioeconômico da Universidade Federal de Santa Catarina Campus Davi Ferreira Lima, Trindade, Florianópolis, SC; CEP 88040-900. 